\title{
ESTRATÉGIAS PARA A PARTICIPAÇÃO DE ALUNOS COM TRANSTORNO DO ESPECTRO AUTISTA EM AULAS DE EDUCAÇÃO FÍSICA
}

\author{
Maria Luiza Salzani Fiorini \\ Eduardo José Mañini
}

\section{Resumo}

Atendo-se à inclusão escolar de alunos com Transtorno do Espectro Autista (TEA) em aulas de Educação Física, as pesquisas indicam que há consideráveis informações sobre as dificuldades dos professores de Educação Física (PEF), bem como, o que o PEF poderia fazer quando há um aluno com TEA em aula. Porém, pouco se sabe sobre as estratégias que os PEF usam em relação a esse aluno. Assim, objetivou-se identificar e descrever as estratégias de professores de Educação Física para promover a participação de alunos com Transtorno do Espectro Autista nas aulas. Três PEF do Ensino Fundamental $\left(1^{\circ}\right.$ ao $5^{\circ}$ ano) e a respectiva turma em que havia um aluno com TEA participaram do estudo. Quatro filmagens de aulas de Educação Física foram realizadas em cada turma. As filmagens foram analisadas a partir da Análise Microgenética. Os PEF utilizaram quatro tipos de estratégias: 1) que antecedem o ensino, com a finalidade de posicionar o aluno ou a turma; 2) para explicação e suporte durante a atividade, tais como explicar a atividade, auxiliar o aluno, e estabelecer limites; 3) que decorrem da ação do aluno, como, respeitar as regras estabelecidas em conjunto; e, 4) para o comportamento emocional do aluno, mais precisamente lidar com a instabilidade emocional e frustações do aluno com TEA. Conclui-se que as estratégias utilizadas pelos PEF se modificaram por meio da interação com alunos. Em determinadas situações uma estratégia foi suficiente, mas em outras, duas ou mais estratégias foram necessárias. Não houve linearidade quanto aos tipos de estratégias, com exceção das estratégias que antecedem o ensino.

Palavras-chave: transtorno do espectro autista; educação física; estratégia; ação.

\section{STRATEGIES FOR THE PARTICIPATION OF STUDENTS WITH AUTISTIC SPECTRUM DISORDER IN PHYSICAL EDUCATION CLASSES}

\begin{abstract}
Regarding inclusive education of students with Autism Spectrum Disorder (ASD) in general Physical Education, there is a large body of information concerning Physical Education teachers' (PETs) difficulties, as well as what teachers could do when there is a student with ASD in class. However, little is known about the strategies that PETs adopt concerning these students. Thus, the objective was to identify and describe the strategies of Physical Education teachers to promote the participation of students with Autism Spectrum Disorder in regular classes. Three Elementary School PETs (1 st to 5th grade) and the respective class, which had a student with ASD, participated in the study. Four physical education lessons were filmed in each class. Filming was analyzed based on microgenetic analysis. The PETs used four types of strategies: 1) Actions that precede teaching, for the purpose of positioning the student or the class; 2) Explanation and support during activities, such as explaining the activity, assisting the student, and setting limits; 3) what arises from Student Actions, such as, respecting the rules established together; and 4) Student Emotional Behavior, more precisely to deal with the student's emotional instability and frustrations with ASD. It can be concluded that the strategies used by the PETs changed through interaction with students. In certain situations, one strategy was sufficient, but in others, two or more strategies were necessary. The strategies that precede the teaching always preceded Explanation and Support during activities. Moreover, Student Emotional Behavior strategies presented sequential actions: to identify why the student presented that behavior;
\end{abstract}


motivate the student to participate; respect the student's will in not wanting to participate for a period of class; motivate again.

Keywords: autism spectrum disorder; physical education; strategies; action.

\title{
ESTRATEGIAS PARA LA PARTICIPACIÓN DE ESTUDIANTES CON TRASTORNO DEL ESPECTRO AUTISTA EN CLASES DE EDUCACIÓN FÍSICA
}

\begin{abstract}
Resumen
Dada la inclusión escolar de estudiantes con Trastorno del Espectro Autista (TEA) en las clases de Educación Física, la investigación indica que existe información considerable sobre las dificultades de los docentes de Educación Física (PEF), así como, lo que PEF podría hacer cuando hay un estudiante con TEA en clase. Sin embargo, se sabe poco sobre las estrategias que utiliza PEF en relación con este alumno. Así, el objetivo fue identificar y describir las estrategias de los profesores de Educación Física para promover la participación de los estudiantes con Trastorno del Espectro Autista en las clases. En el estudio participaron tres PEF de Educación Primaria ( $1^{\circ}$ a $5^{\circ}$ año) y la respectiva clase en la que había un alumno con TEA. Se filmaron cuatro clases de educación física en cada clase. La filmación se analizó mediante análisis microgenético. PEF utilizó cuatro tipos de estrategias: 1) que preceden a la enseñanza, con el propósito de posicionar al alumno o la clase; 2) para explicación y apoyo durante la actividad, como explicar la actividad, ayudar al estudiante y establecer límites; 3) que resulten de la acción del estudiante, cómo respetar las reglas establecidas en conjunto; y 4) por el comportamiento emocional del estudiante, más precisamente para lidiar con la inestabilidad emocional y las frustraciones del estudiante con TEA. Se concluye que las estrategias utilizadas por el PEF fueron modificadas a través de la interacción con los estudiantes. En determinadas situaciones, una estrategia era suficiente, pero en otras, eran necesarias dos o más estrategias. No hubo linealidad en cuanto a los tipos de estrategias, a excepción de las estrategias que preceden a la enseñanza.
\end{abstract}

Palabras clave: trastorno del espectro autista; educación física; estrategia; acción.

\section{INTRODUÇÃO}

A inclusão escolar, no presente texto, refere-se ao acesso, a participação e a aprendizagem, com vistas à escolarização da população-alvo da Educação Especial, do qual faz parte estudantes com Transtorno do Espectro Autista (BRASIL, 2008, 2012).

Particularmente em relação aos estudantes com Transtorno do Espectro Autista (TEA), a literatura na área de Educação Física tem afirmado que muitos professores de Educação Física $(\mathrm{PEF})$ se sentem frustrados porque acreditam que a inclusão escolar desses alunos é por vezes difícil e, para alguns, até impossível (ZHANG; GRIFFIN, 2007).

Alguns estudos têm descrito as dificuldades de PEF para criar condições favoráveis à inclusão escolar de alunos com TEA.

Vaz e Santos (2009), ao entrevistarem PEF, questionaram sobre os limites e as possibilidades do aluno com TEA. Todavia, os professores não deixaram claro quais seriam as implicações, as modificações realizadas e as estratégias não foram explicitadas.

Fiorini e Manzini (2014), ao ouvirem PEF, identificaram que as dificuldades estavam inseridas em diversos temas, tais como: 1) formação; 2) questão administrativo-escolar; 3) alunos; 4) diagnóstico; 5) família; 6) recurso pedagógico; 7) estratégia de ensino; e, 8) Educação Física como componente curricular.

Souza e Assis (2015) destacaram as dificuldades relatadas por PEF, sendo elas: 1) falta de orientação sobre o TEA; 2) falta de pessoas capacitadas; 3) ausência da família; 4) pouca interação 
e comunicação entre os professores a respeito dos alunos com TEA; e, 5) o comportamento do aluno, que poderia, por exemplo, atrapalhar a aula e causar desconforto.

Ao estudarem sobre as dificuldades e sucessos de professores de Educação Física em relação à inclusão escolar, Fiorini e Manzini (2016), por meio de filmagens de aulas, identificaram que as dificuldades estavam relacionadas à seleção do conteúdo; à estratégia de ensino; ao recurso pedagógico; à falta de ação propositiva em relação à inclusão; e, à presença da professora de sala durante a aula de Educação Física.

Se, por um lado, a literatura aponta as dificuldades para a inclusão escolar de estudantes com TEA, por outro, os pesquisadores também estão preocupados em tentar buscar procedimentos para superar essas dificuldades. Para Lindsay et al. (2014), muitas pesquisas têm focado nos desafios do professor de Educação Física para incluir um aluno com TEA ou nas percepções sobre a inclusão, mas pouco se sabe sobre as estratégias que o professor usa para incluir esse aluno.

Nessa mesma direção, Menear e Smith (2011) afirmaram que quando as estratégias adequadas suprem as necessidades do estudante com TEA, a aula de Educação Física torna-se momento muito positivo na vida desse estudante. Portanto o espaço, os materiais e a organização da aula são importantes, mas são necessárias estratégias que possibilitem a intervenção do professor de Educação Física.

Os pesquisadores da área de Educação Física utilizam diversas nomenclaturas para se referir às possíveis ações do PEF em relação à inclusão escolar de alunos com TEA, como, cuidados, dicas, estratégias e técnicas de ensino. No presente texto utilizar-se-á o termo estratégia.

Para definição neste manuscrito, estratégia é toda ação do professor no momento de ensino ou de avaliação, sendo flexível e passível de ser modificada caso se constate a não funcionalidade para o aluno. Para tanto, deve-se levar em consideração as características da deficiência, as potencialidades do aluno e o objetivo da atividade (MANZINI, 2010). Toda estratégia ao ser utilizada tem uma intenção por parte daquele que a utiliza (FIORINI; MANZINI, 2018).

Tendo como base um levantamento em publicações nacionais e internacionais foi possível arrolar sete tipos de estratégias que poderiam ser utilizadas por PEF em relação ao aluno com TEA, sendo elas para: 1) estabelecer rotina; 2) explicar uma atividade; 3) chamar a atenção do aluno; 4) formar turmas; 5) conduzir a atividade; 6) o comportamento do aluno e, 7) comunicar com o aluno.

Com relação à estratégia de estabelecer rotina, um único exemplo foi identificado em diversos estudos, sendo sugerido ao PEF: ter sempre um começo e um ponto final para cada atividade (HOUSTON-WILSON; LIEBERMAN, 2009; MENEAR; SMITH, 2011; ZHANG; GRIFFIN, 2007).

Outro tipo de estratégia recomendada pelos autores é para explicar a atividade, por meio de ações do PEF como: 1) demonstrar a atividade para o aluno imitar (GRENIER; YEATON, 2011; ZHANG; GRIFFIN, 2007); 2) oferecer orientações verbais de forma curta, concreta e simples (MENEAR; SMITH, 2011; NEUMEIER, 2015; ZHANG; GRIFFIN, 2007); 3) oferecer instrução individualizada (ZHANG; GRIFFIN, 2007); e, 4) minimizar os jargões ou gírias (ZHANG; GRIFFIN, 2007). A literatura da área sugere, também, uma estratégia para o PEF chamar a atenção do aluno com TEA: levantar a mão ao invés de usar barulho ou som (MENEAR; SMITH, 2011).

Para o PEF formar turmas, a única estratégia recomendada é para trabalhar com atividades individuais ou em grupos de no máximo três alunos (MENEAR; SMITH, 2011).

As dicas dos autores para o PEF conduzir uma atividade, quando há um aluno com TEA na turma, são: 1) fornecer feedback (MENEAR; NEUMEIER, 2015); 2) participar da atividade para envolver o aluno (ZHANG; GRIFFIN, 2007); 3) ajudar o aluno quando ele não souber o que 
fazer, e redirecioná-lo quando estiver fazendo algo diferente (LIEBERMAN; HOUSTONWILSON, 2009); 4) propor atividades de expressão corporal, ritmo e dança (BEZERRA, 2010); 5) determinar os limites da área de jogo por meio de bandeiras, cones, marcas e linhas no chão (FITTIPALDI-WERT; MENEAR; NEUMEIER, 2015; MENEAR; SMITH, 2011; MOWLING, 2009); e, 6) usar colegas tutores (ZHANG; GRIFFIN, 2007).

O outro tipo de estratégia, que a literatura preconiza, é para o comportamento do aluno com TEA. As ações do PEF devem ser na direção de: 1) identificar o quê faz com que o aluno fique bravo, frustrado e feliz (LIEBERMAN; HOUSTON-WILSON, 2009); 2) usar música para acalmar (AUXTER et al., 2010); 3) aceitar a vontade do aluno em não querer participar, pois, a insistência pode causar um efeito contrário (BEZERRA, 2010); e, 4) usar abordagens reativas, como o timeout e a advertência verbal (ZHANG; GRIFFIN, 2007).

$\mathrm{O}$ último tipo de estratégia recorrente nas publicações refere-se à comunicação. As sugestões são para o PEF: 1) identificar como o aluno se comunica (ZHANG; GRIFFIN, 2007); e, 2) utilizar uma comunicação efetiva (FITTIPALDI-WERT; MOWLING, 2009).

Diante das estratégias apresentadas, fica evidente que há consideráveis informações, na literatura, sobre o quê e como o PEF poderia fazer quando há um aluno com TEA em suas aulas. Porém, retomando o argumento de Lindsay et al. (2014, p.118) "[...] pouco se sabe sobre as estratégias que o PEF usa para incluir esse aluno". Nesse sentido, assume-se como problema de pesquisa as seguintes questões: quais são as ações do PEF para incluir o aluno com TEA? Que estratégias o PEF utiliza, nas turmas regulares em há um aluno com TEA, para oportunizar a participação desse aluno juntamente com os demais alunos?

\section{OBJETIVO}

Identificar e descrever as estratégias de professores de Educação Física para promover a participação de alunos com Transtorno do Espectro Autista nas aulas regulares.

\section{MÉTODO}

A pesquisa tem fundamentação qualitativa-descritiva instrumentalizada pela Análise Microgenética (BEZERRA, 2010; MEIRA, 1994; PETERS; ZANELLA, 2002).

\section{Participantes}

Três PEF da rede municipal de ensino, do $1^{\circ}$ ao $5^{\circ}$ ano, de uma cidade no centro-oeste do estado de São Paulo participaram da pesquisa1. Cada professor ministrava aulas para uma turma regular em que havia um aluno com TEA matriculado.

Três critérios foram utilizados para selecionar os PEF: 1) entre os participantes de uma pesquisa sobre estratégias para promover a participação de alunos com TEA em aulas regulares de Educação Física, que complementa o presente estudo, foram selecionados os que relataram que não encontravam dificuldades e que conseguiam criar condições para inclusão escolar do aluno com TEA; 2) aceitaram, voluntariamente, a participar da pesquisa; 3) lecionavam em turmas regulares nas quais todos os alunos possuíam autorização dos responsáveis para realização de filmagens.

\footnotetext{
1 Obteve-se a aprovação do Comitê de Ética da Faculdade onde a pesquisa foi realizada: Parecer n. 1.054.257.
} 
Os três PEF foram denominados como: PEF1, PEF2 e PEF3. Para os três alunos foram atribuídas as abreviações: L., R. e E. Dessa forma, formaram-se três díades: PEF1-L., PEF2- R. e PEF3-E. Na Tabela1, a seguir, apresenta-se a caracterização das três díades de participantes.

Tabela 1: Caracterização das três díades de participantes

\begin{tabular}{|c|c|c|}
\hline $\begin{array}{c}\text { DÍADE DE } \\
\text { PARTICIPANTES }\end{array}$ & $\begin{array}{l}\text { CARACTERÍSTICAS DO PROFESSOR } \\
\text { DE EDUCAÇÃO FÍSICA }\end{array}$ & $\begin{array}{c}\text { CARACTERÍSTICAS DO ALUNO COM TRANSTORNO } \\
\text { DO ESPECTRO AUTISTA }\end{array}$ \\
\hline PEF1 - L. & $\begin{array}{l}\text { - Sexo: masculino; } \\
\text { - } 44 \text { anos de idade; } \\
\text { - De } 4 \text { a } 6 \text { anos de experiência como docente } \\
\text { em escolas regulares; } \\
\text { - De } 4 \text { a } 6 \text { anos de experiência docente com } \\
\text { alunos com deficiência. }\end{array}$ & $\begin{array}{l}\text { - Sexo: masculino; } \\
\text { - } 4^{\circ} \text { ano; } \\
\text { - Comunicação por meio da fala, mas com comprometimento na } \\
\text { comunicação verbal; } \\
\text { - Interação social limitada - mínima ou nenhuma resposta ao } \\
\text { contato social com outras pessoas; } \\
\text { - Desconforto e frustração com a interrupção de rotinas. }\end{array}$ \\
\hline PEF2 - R. & $\begin{array}{l}\text { - Sexo: feminino; } \\
\text { - } 44 \text { anos de idade; } \\
\text { - De } 4 \text { a } 6 \text { anos de experiência como docente } \\
\text { em escolas regulares; } \\
\text { - De } 4 \text { a } 6 \text { anos de experiência docente com } \\
\text { alunos com deficiência. }\end{array}$ & $\begin{array}{l}\text { - Sexo: masculino; } \\
\text { - } 3^{\circ} \text { ano; } \\
\text { - Comunicação por meio da fala; } \\
\text { - Padrões estereotipados e repetitivos de comportamento motor; } \\
\text { - Apresentava respostas reduzidas ao contato social com outras } \\
\text { pessoas. }\end{array}$ \\
\hline PEF3 - E. & $\begin{array}{l}\text { - Sexo: feminino; } \\
\text { - } 30 \text { anos de idade; } \\
\text { - De } 4 \text { a } 6 \text { anos de experiência como docente } \\
\text { em escolas regulares; } \\
\text { - De } 4 \text { a } 6 \text { anos de experiência docente com } \\
\text { alunos com deficiência. }\end{array}$ & $\begin{array}{l}\text { - Sexo: masculino; } \\
\text { - } 3^{\circ} \text { ano; } \\
\text { - Comunicação por meio da fala, mas com uso restrito da } \\
\text { comunicação verbal; } \\
\text { - Respostas reduzidas ao contato social com outras pessoas. }\end{array}$ \\
\hline
\end{tabular}

Fonte: elaboração própria, 2021.

Procedimentos para a coleta dos dados

Quatro aulas de Educação Física, de cada díade de participantes, foram registradas por meio de filmagens, totalizando 12 aulas. O número de registros baseou-se na tendência à repetição das informações a partir da terceira filmagem (BEZERRA, 2010).

As aulas foram filmadas na íntegra, com duração de 50 minutos, e o foco foi o PEF e o aluno com TEA. Utilizou-se uma filmadora afixada em um tripé, na diagonal da quadra, e as funções de rotação e zoom foram conduzidas pela pesquisadora. O posicionamento da filmadora foi definido após um estudo piloto.

Tratamento e análise dos dados

$\mathrm{Na}$ Análise Microgenética a atenção está nos detalhes das ações e no recorte de episódios interativos, que permitem analisar, em detalhes, as mudanças relativamente sutis nas relações entre agentes e suas ações (MEIRA, 1994).

Dessa forma, quatro passos foram desenvolvidos para analisar os filmes, conforme as orientações de Meira (1994) e Peters e Zanella (2002):

1) Assistir aos 12 filmes na íntegra, e realizar anotações que remetessem às estratégias utilizadas pelos PEF, isso é, as ações visando à inclusão escolar do aluno com TEA;

2) Elaborar um índice de eventos significativos, isso é, uma lista com os tipos de estratégias identificadas, independentemente de qual professor as tenha implementado. Para tanto, as estratégias identificadas foram separadas e reagrupadas, primeiramente, por semelhança quanto ao tipo e, posteriormente, dentro de cada tipo, quanto à finalidade; 
3) Assistir novamente aos filmes e, a partir do índice de eventos significativos, selecionar os episódios interativos que exemplificassem as estratégias identificadas. Quando dois ou mais professores estabeleceram a mesma estratégia, o episódio de cada professor foi selecionado;

4) Transcrever, literalmente, todos os episódios selecionados, com atenção às ações e às interações das três díades de participantes.

A fim de demonstrar o tratamento de dados, serão apresentados dois episódios interativos.

\section{Episódio A}

O contexto desse episódio refere-se a um evento ocorrido na turma do aluno R., em que os alunos estavam sentados, no chão da quadra, juntamente com a PEF2, a qual realizava a chamada. Nesse momento, há uma interação entre a PEF2 e aluno com TEA:

PEF2: Ao terminar a chamada, orienta verbalmente todos os alunos sobre o que eles devem fazer: - "Vocês vão levantar, bem bonitinho, e fazer um círculo lá na quadra".

Rapidamente os alunos caminham para o centro da quadra e se sentam um ao lado do outro, formando um círculo.

R.: Não vai para o centro da quadra, mas caminha e se senta no primeiro degrau da arquibancada.

PEF2: Ao observar que o R. não foi para o círculo, chama-o: - "R.".

R.: Fala repetidamente a palavra "não" enquanto caminha até o círculo formado pelos demais alunos.

PEF2: Com todos os alunos sentados, um ao lado do outro, inicia a atividade dizendo: - "Vamos lá".

Os alunos, sentados, alongam as duas pernas à frente do corpo e mantem a ponta dos pés para cima.

R.: Olha para a aluna sentada a sua esquerda, observa o movimento que ela está fazendo, e realiza o mesmo movimento.

Conforme destacado no episódio, o PEF utilizou uma estratégia que foi denominada de Estratégia que Antecede o Ensino, que compreende toda ação do PEF antes do momento de ensino de uma atividade, sendo crucial para que tanto o ensino quanto a realização da atividade possam acontecer em condições favoráveis à inclusão escolar do aluno com TEA. Particularmente neste episódio, a Estratégia que Antecede o Ensino teve como finalidade posicionar a turma. Observa-se que a ação do PEF foi de posicionar os alunos em círculo, um ao lado do outro, para a realização do alongamento.

Fica evidente que essa estratégia não foi adotada individualmente para o aluno com TEA, mas para a turma como um todo. Ao posicionar a turma em círculo, com alunos ao lado e a frente do aluno com TEA, foi uma estratégia bem-sucedida, pois, pode favorecer a imitação motora do aluno com TEA.

\section{Episódio B}

Tendo como contexto a turma do aluno E., o episódio refere-se a um momento da aula em que a PEF3 e os alunos estavam em pé, um ao lado do outro, formando um círculo, e o alongamento foi iniciado. Nesse contexto, a PEF3 e o aluno com TEA interagiram:

PEF3: Explica o movimento a ser realizado dizendo: - "Afastou os pés, subiu os braços". Concomitantemente eleva os dois braços acima da cabeça e entrelaça os dedos. 
E.: Olha para a PEF, espera até que ela demonstre e, em seguida, repete o movimento demonstrado, mas não conta até dez.

Os demais alunos fazem o mesmo movimento e contam até dez.

PEF3: Verbaliza como realizar o próximo movimento: - "Para o lado". Enquanto explica verbalmente mantem os dois braços elevados acima da cabeça e os dedos entrelaçados, além de inclinar o tronco e os braços ligeiramente para a esquerda. E.: Olha para a PEF e inclina o tronco exatamente como demonstrado.

A partir do episódio é possível identificar que o PEF utilizou uma que foi denominada Estratégia para Explicação e Suporte Durante a Atividade, que perpassa as ações do PEF para explicar a atividade, reforçar um comportamento (feedback), preparar o aluno com TEA para a realização da atividade, prestar assistência física, oferecer estímulo instigador visual, delimitar a área/espaço da atividade, e selecionar o conteúdo.

Particularmente nesse episódio, a intenção foi explicar a atividade, por meio da ação do PEF em verbalizar o movimento a ser realizado e, concomitantemente, demonstrar como fazế-lo, para todos os alunos. A característica dessa estratégia que a torna bem-sucedida visando à inclusão escolar do aluno com TEA é que a PEF, ao mesmo tempo, verbalizou e demostrou o movimento.

Diante dos dois episódios interativos, entende-se que o tratamento aplicado aos dados permitiu visualizar o processo, como prevê a Análise Microgenética, e que se alinha a definição de estratégia de ensino adotada neste texto. A partir desse processo, foi possível identificar e descrever cada uma das estratégias de ensino utilizadas e classificá-las pelo nome, finalidade e pela ação do professor de Educação Física.

Todas as estratégias identificadas foram descritas, tendo como padrão iniciar, sempre, com um verbo no infinitivo, para, assim, indicar uma ação (MANZINI, 2010).

\section{RESULTADOS E DISCUSSÃO}

A classificação das estratégias pode ser identificada na Tabela 2, que segue.

Tabela 2: Estratégias, finalidades e ações do professor de Educação Física

\begin{tabular}{|c|c|c|}
\hline TIPO DE ESTRATÉGIA & FINALIDADE & AÇÃO DO PROFESSOR DE EDUCAÇÃO FÍSICA \\
\hline \multirow{2}{*}{$\begin{array}{l}\text { Estratégia que antecede o } \\
\text { ensino }\end{array}$} & Posicionar a turma & Posicionar os alunos em círculo, um ao lado do outro \\
\hline & Posicionar o aluno com TEA & $\begin{array}{l}\text { Garantir que o aluno com TEA estivesse junto aos demais alunos para } \\
\text { que pudesse iniciar a explicação verbal e a demonstração da atividade. }\end{array}$ \\
\hline \multirow[t]{8}{*}{$\begin{array}{l}\text { Estratégia para explicação e } \\
\text { suporte durante a atividade }\end{array}$} & \multirow{2}{*}{ Explicar a atividade } & $\begin{array}{l}\text { Verbalizar o movimento a ser realizado e, concomitantemente, } \\
\text { demonstrar como fazê-lo, para todos os alunos }\end{array}$ \\
\hline & & $\begin{array}{l}\text { Instruir a atividade para todos com alunos e, em seguida, explicar } \\
\text { individualmente para o aluno com TEA, de forma simples e objetiva }\end{array}$ \\
\hline & $\begin{array}{l}\text { Reforçar um comportamento do } \\
\text { aluno com TEA }\end{array}$ & $\begin{array}{l}\text { Proporcionar feedback positivo, por meio de reforço verbal, como o } \\
\text { elogio, para motivar o aluno com TEA após o entendimento da } \\
\text { explicação da atividade }\end{array}$ \\
\hline & $\begin{array}{l}\text { Preparar o aluno com TEA no } \\
\text { início da atividade }\end{array}$ & $\begin{array}{l}\text { Oferecer um estímulo de preparação, por meio de informações verbais } \\
\text { e visuais, antecipando o quê o aluno com TEA deveria fazer naquele } \\
\text { momento da atividade }\end{array}$ \\
\hline & $\begin{array}{l}\text { Auxiliar o aluno com TEA na } \\
\text { realização da atividade }\end{array}$ & $\begin{array}{l}\text { Prestar a assistência física quando a explicação verbal e a demonstração } \\
\text { não forem suficientes, isso é, guiar o movimento do aluno com TEA } \\
\text { conforme a atividade proposta }\end{array}$ \\
\hline & \multirow[t]{2}{*}{$\begin{array}{l}\text { Estabelecer limites para a } \\
\text { atividade }\end{array}$} & $\begin{array}{l}\text { Oferecer estímulo visual, como os gestos e os movimentos corporais, } \\
\text { instigando o aluno com TEA para que continuasse a sua participação } \\
\text { na atividade }\end{array}$ \\
\hline & & $\begin{array}{l}\text { Demarcar a área para a realização da atividade por meio de um estímulo } \\
\text { visual, como a linha colorida pintada no chão da quadra }\end{array}$ \\
\hline & Selecionar o conteúdo da aula & Utilizar a música \\
\hline $\begin{array}{l}\text { Estratégia que decorre da } \\
\text { resposta ou ação do aluno }\end{array}$ & $\begin{array}{l}\text { Respeitar as regras estabelecidas } \\
\text { em conjunto }\end{array}$ & $\begin{array}{l}\text { Manter as regras tanto para o aluno com TEA quanto para os demais } \\
\text { alunos }\end{array}$ \\
\hline
\end{tabular}


DOI: $10.12957 /$ teias.2021.56939

\begin{tabular}{|l|l|l|}
\hline \multirow{5}{*}{} & $\begin{array}{l}\text { Lidar com a não aceitação das } \\
\text { regras }\end{array}$ & $\begin{array}{l}\text { Conversar com o aluno com TEA e contextualizar a regra para que o } \\
\text { aluno entendesse que ele sentaria apenas uma rodada e voltaria para a } \\
\text { atividade }\end{array}$ \\
\cline { 2 - 3 } & $\begin{array}{l}\text { Evitar a exclusão do aluno com } \\
\text { TEA }\end{array}$ & $\begin{array}{l}\text { Orientar verbalmente os alunos da turma para que formassem grupo, } \\
\text { também, com o aluno com TEA }\end{array}$ \\
\cline { 2 - 3 } & $\begin{array}{l}\text { Promover a participação do } \\
\text { aluno com TEA }\end{array}$ & $\begin{array}{l}\text { Identificar quando o aluno com TEA se aproximasse do grupo e } \\
\text { apresentasse iniciativa em querer participar da atividade e, com estímulo } \\
\text { verbal e visual, criar condições para que ele participasse }\end{array}$ \\
\hline \multirow{5}{*}{$\begin{array}{l}\text { Estratégia para lidar com o } \\
\text { comportamento emocional do } \\
\text { aluno }\end{array}$} & $\begin{array}{l}\text { Lidar com a instabilidade } \\
\text { emocional e com as frustações } \\
\text { do aluno com TEA }\end{array}$ & $\begin{array}{l}\text { Motivar, constantemente, o aluno com TEA para participar da aula, } \\
\text { mas respeitar a vontade dele quando identificar que não queria realizar } \\
\text { uma determinada atividade }\end{array}$ \\
\cline { 2 - 3 } & $\begin{array}{l}\text { Participar da atividade para que o aluno com TEA se motivasse a } \\
\text { também participar }\end{array}$ \\
\cline { 2 - 3 } & $\begin{array}{l}\text { Lidar com a frustação do aluno com TEA em relação ao perder e, por } \\
\text { meio do diálogo, relembrar e enfatizar as vitórias que ele teve durante a } \\
\text { atividade }\end{array}$ \\
\hline
\end{tabular}

Fonte: elaboração própria, 2021.

\section{Estratégia que antecede o ensino}

A Estratégia que antecede o ensino teve como finalidade posicionar o aluno ou a turma. Para Schopler et al. (1990), o estudante com autismo aprende a se comportar quando são proporcionadas interações sociais que facilitam entender como ele deve se comportar. Em círculo, todos os alunos podem ser modelo uns para os outros (ZHANG; GRIFFIN, 2007). O impacto da estratégia utilizada pelo PEF pode ser identificado no final da descrição do episódio interativo, quando o aluno com TEA olha para a aluna ao seu lado, observa o movimento que ela está fazendo, no alongamento, e faz o mesmo movimento.

Mas por que essa estratégia é importante para promover a participação do aluno com TEA nas atividades da aula de Educação Física? Conforme esclareceram Fittipaldi-Wert e Mowling (2009, p.40), como “[...] os alunos com autismo podem ser não-verbais e ter uma linguagem mínima", podem ter dificuldades para compreender a língua falada. Grenier e Yeaton (2011) descreveram que alguns alunos com TEA podem perder importantes explicações verbais, necessárias para o desenvolvimento de habilidades, principalmente, em turmas grandes e dentro de espaços como a quadra ou o ginásio. Desse modo, a explicação verbal pode não ser a forma mais produtiva de transmitir informação para esse aluno. De acordo com Menear e Smith (2011, p.22), os "alunos com autismo" não processam informação verbal tão bem quanto a informação visual. Por isso, é imprescindível que o PEF, ao explicar uma atividade, também a demonstre (ZHANG; GRIFFIN, 2007). Nesse caso em específico, a explicação verbal e a demonstração foram simultâneas.

\section{Estratégia para explicação e suporte durante a atividade}

A Estratégia para explicação e suporte durante a atividade teve como uma das finalidades explicar a atividade, podendo instruir a atividade para todos com alunos e, em seguida, explicar individualmente para o aluno com TEA, de forma simples e objetiva.

A instrução individualizada foi mencionada por Zhang e Griffin (2007, p.34) como uma das oito possíveis soluções para incluir "alunos com autismo" em aulas regulares de Educação Física. Para os autores, quando o PEF oferece instrução individualizada, os "alunos com autismo" são mais propensos a participar das atividades da aula. Desse modo, trata-se de uma estratégia favorável à participação, sendo que diferentes autores defendem que o princípio consensual da inclusão escolar é, justamente, a participação (BRASIL, 2008; ODOM, 2000). 
Outra Estratégia para explicação e suporte durante a atividade refere-se a reforçar um comportamento do aluno com TEA. A ação do PEF identificada no vídeo foi a de proporcionar feedback positivo, por meio de reforço verbal, como o elogio, para motivar o aluno com TEA após o entendimento da explicação da atividade.

O feedback positivo é fundamental para a aprendizagem, e deve ser oferecido depois que o aluno finaliza a tarefa, quando demonstra esforço ou quando segue uma instrução, por exemplo, por meio de elogio verbal ou bater palma (FOLSOM-MEEK; AIELLO, 2007). O feedback positivo é um reforçador, que pode ter como consequência o aumento ou a manutenção do comportamento enfatizado, e a probabilidade de ele ocorrer, com maior frequência, em situações futuras (IÑESTA, 1974). Especialmente para o aluno com TEA, é preciso que o feedback seja fornecido constantemente (MENEAR; NEUMEIER, 2015).

Preparar o aluno com TEA no início da atividade também se refere a uma Estratégia para explicação e suporte durante a atividade. O intuito dessa estratégia é preparar o aluno com TEA para realizar a atividade. A ação do PEF identificada no vídeo foi a de oferecer um estímulo de preparação, por meio de informações verbais e visuais, antecipando verbalmente o quê o aluno com TE $A$ deveria fazer naquele momento da atividade.

$\mathrm{Na}$ atividade proposta pelo PEF, seis alunos realizavam a atividade e, os demais, aguardavam nas filas. Em decorrência dessa espera e do tempo decorrido desde a explicação inicial da atividade, a ação de sucesso do PEF foi, assim que o aluno com TEA iniciou a sua participação na atividade, relembrá-lo verbalmente o quê deveria fazer. Como definiu Iñesta (1974, p.37), tratase de um estímulo de preparação, por meio do qual se consegue "extrair" ou "facilitar" um comportamento.

Nessa direção, Farinha (2012, p.23) esclareceu que “[...] frequentemente os alunos com autismo não se lembram da ordem precisa das tarefas, porque eles se atêm a detalhes específicos e nem sempre veem relação entre eles". Desse modo, assim como a estratégia utilizada pela PEF, Lieberman e Houston-Wilson (2009) afirmaram que o PEF pode ajudar o aluno com TEA quando ele não souber o que fazer.

Auxiliar o aluno com TEA na realização da atividade refere-se a uma Estratégia para explicação e suporte durante a atividade. A ação do PEF foi de prestar a assistência física (instigação física) quando a explicação verbal e a demonstração não forem suficientes, isso é, guiar o movimento do aluno com TE $A$ conforme a atividade proposta.

Nota-se que a assistência física somente deve ser oferecida após identificar que, principalmente a demonstração fornecida, por coleta ou professor, não seja suficiente para o entendimento do aluno. Essa sequência de primeiramente explicar e demonstrar e, somente depois, prestar ajuda física é a recomendação de outros autores que também utilizaram essa estratégia (FOLSOM-MEEK; AIELLO, 2007; LIEBERMAN; HOUSTON-WILSON, 2009).

Essa estratégia foi definida por Iñesta (1974) como instigação física, isso é, um estímulo utilizado na modelagem da resposta. De acordo com Craft (1996) consiste em guiar o movimento do aluno nas posições adequadas e necessárias para a realização da atividade, sendo aceitável e preferível do que deixar o aluno fora de uma atividade.

Estabelecer limites para a atividade é uma Estratégia para explicação e suporte durante a atividade. Identificou-se pela ação do PEF em demarcar a área para a realização da atividade por meio de um estímulo visual, como a linha colorida pintada no chão da quadra.

Autores como Fittipaldi-Wert e Mowling (2009), Houston-Wilson e Lieberman (2009) e Menear e Smith (2011), ao discutirem estratégias para a inclusão escolar de alunos com TEA, também identificaram a necessidade de os PEF marcar, claramente, os limites da área de cada atividade, isso é, determinar exatamente a área de jogo. Assim como fez a PEF, os autores sugerem 
que esse limite seja concreto e perceptível visualmente como por exemplo, cone, bandeira, fitas, linhas ou marcas no chão. A PEF utilizou a linha amarela pintada no chão da quadra.

Essa estratégia tem implícito o oferecimento de uma informação visual transmitida pela marca, seja ela uma linha, um cone ou uma fita. A PEF determinou que a atividade do pega-pega ocorreria apenas dentro dos limites da linha amarela da quadra. A ideia era que os alunos permanecessem dentro do espaço demarcado. Mas, porque utilizar uma estratégia com essa caraterística quando há um aluno com TEA na turma? Fittipaldi-Wert e Mowling (2009, p.42) explicaram que os suportes visuais, ou informações visuais, proporcionam expectativas claras aos "alunos com autismo", oferecem uma organização previsível dos eventos e indicam as alterações que podem ocorrer ao longo da atividade.

Selecionar o conteúdo da aula também é uma Estratégia para explicaşão e suporte durante a atividade. A finalidade dessa estratégia foi selecionar o conteúdo da aula, por meio da ação da PEF em utilizar a música.

A PEF utilizou um conteúdo diversificado, que não enfatizava nem a competição nem o esporte e que, além disso, possuía características favoráveis ao aluno com TEA. O atributo bemsucedido dessa estratégia apoia-se nos argumentos de Tomé (2007, p.244). Para o autor, o uso de conteúdos e atividades complexas e "[...] não coerentes com a cultura da comunidade" como, jogos desportivos com regras, gincanas e jogos imaginário, dificultam a aprendizagem e causa frustração no aluno, em função da "tríade autística", já que o "[...] aluno com autismo pode não distinguir com a facilidade o real do imaginário". Desse modo, Tomé (2007) afirmou que o PEF pode optar por atividades cíclicas como é o caso da música.

A música auxilia na redução de comportamentos estereotipados, além de poder encorajar o relaxamento (AUXTER et al., 2010; TOMÉ, 2007).

\section{Estratégia que decorre da resposta ou ação do aluno com TEA}

As Estratégias que decorrem da resposta on ação do aluno com TE $A$ são reações a um comportamento específico do aluno com TEA e que demanda uma estratégia diferente, que não é nem prévia ou para o ensino. A primeira delas que foi identificada teve a finalidade de respeitar as regras estabelecidas com a turma. A ação do PEF foi de manter as regras tanto para o aluno com TE $A$ quanto para os demais alunos. Uma segunda teve a intenção de lidar com a não aceitação das regras: conversar com o aluno com TE $A$ e contextualizar a regra para que o aluno entendesse que ele sentaria apenas uma rodada e voltaria para a atividade quando tivesse cometido algo que estava fora da regra do jogo ou brincadeira.

As regras, apenas em nível verbal, sem apoio visual, podem ser algo abstrato para o aluno com TEA. Como esclarecido no DSM-V, os alunos com TEA podem possuir características diagnósticas como: sofrimento e/ou dificuldade em mudar as ações, inflexibilidade de comportamento e dificuldade em trocar de atividade (APA, 2014).

As ações contidas nesse episódio permitiram identificar outra Estratégia que decorre da resposta ou ação do aluno com TE $A$, a qual teve como intuito promover a participação do aluno com TEA. A ação do PEF foi de identificar quando o aluno com TEA se aproximasse do grupo e apresentasse iniciativa em querer participar da atividade e, por meio de estímulo verbal e visual, criar condições para que ele participasse da atividade.

Essa estratégia tem implícito o olhar atento e a sensibilidade do PEF, o qual soube identificar o momento em que o aluno com TEA deveria ser motivado, encorajado e chamado para participar da atividade. Antes dessa ação do PEF, o aluno com TEA estava sentado, pois não quis participar, mesmo tendo sido motivado pelo PEF. Porém, no momento em que ele se aproximou 
dos demais alunos e do professor, foi a oportunidade para que o PEF explorasse essa iniciativa do aluno e o promovesse condições para que ele participasse.

\section{Estratégia para lidar com o comportamento emocional do aluno}

A Estratégia para lidar com o comportamento emocional do aluno com TE $A$, tem como finalidade ações no sentido de trabalhar a instabilidade emocional, ou com as frustações do aluno com TEA, ou por recursar-se a participar das atividades.

Essa estratégia foi identificada em várias situações nos vídeos, em uma delas, o aluno não queria participar. A ação da PEF foi de dialogar com o aluno com TE $A$ e fazer perguntas diretas para descobrir o motivo para que ele não quisesse participar da atividade.

Assim como sugeriram Lieberman e Houston-Wilson (2009, p.86), o PEF pode descobrir o que faz com que o "aluno com autismo" fique bravo, frustrado e feliz. A estratégia usada pela PEF foi nessa direção, isso é, percebendo que o aluno com TEA não queria participar, aproximouse e, por meio do diálogo - com perguntas claras e diretas - identificou que ele estava ansioso e preocupado com algo que aconteceria no dia seguinte. Após a conversa, a PEF motivou-o a se juntar aos demais alunos.

Outras ações foram identificadas na categoria Estratégia para lidar com o comportamento emocional do aluno com TE $A$, tais como: motivar, constantemente, o aluno com TE $A$ para participar da aula, mas respeitar a vontade dele quando identificasse que não queria realizar uma determinada atividade.

Bezerra (2010) afirmou que "[...] esse tipo de estratégia demonstra certa prudência" do PEF, pois, a insistência exacerbada para que o aluno participe pode causar um efeito contrário.

Uma das ações comuns com alunos com TEA é lidar com a frustação do aluno com TE $A \mathrm{em}$ relação ao perder e, por meio do diálogo, relembrar e enfatizar as vitórias que ele teve durante a atividade.

É preciso mencionar que, em outros momentos dessa mesma atividade do voleibol, o aluno com TEA teve a experiência de ganhar. Entretanto, no momento exato ao qual o episódio remete, a experiência foi de perder. Além disso, atrelado ao perder o jogo tinha a consequência de sair da quadra e retornar para a fila, onde aguardaria para jogar novamente. $\mathrm{O}$ que o aluno queria era continuar na quadra, no jogo. A frustração foi demonstrada pela expressão facial, pelos braços cruzados e pelo choro.

O PEF usou uma abordagem reativa, conforme definido por Zhang e Griffin (2007), isso é, a experiência naquele momento remetia ao perder, mas o PEF focou nas vezes em que ele tinha ganhado; a consequência do perder o jogo era sair da quadra, logo, o PEF relembrou o aluno que ele jogaria novamente, na sequência da atividade. Mais uma vez, o PEF utilizou o diálogo e o esclarecimento da situação para lidar com um comportamento do aluno com TEA.

\section{CONCLUSÕES}

O tratamento de dados, por meio da Análise Microgenética, permitiu focalizar o processo de interações verbais e não verbais entre o PEF e os alunos com TEA ao usar as estratégias de ensino. Somente a partir desse processo é que foi possível realizar a identificação das estratégias, a nomeação, a descrição das finalidades e a descrição das ações.

Os dados permitem concluir que as estratégias foram bem-sucedidas, pois criaram condições para a participação dos alunos com TEA nas mesmas atividades proporcionadas a todos os alunos da turma. Uma estratégia bem-sucedida, para a inclusão escolar, é aquela que não limita a atuação do PEF, mas que é selecionada, mantida, alterada ou complementada por outra, em decorrência das características do aluno com TEA e da atividade proposta pelo professor. 
A partir da identificação da várias estratégias foi possível constatar a existência de 12 estratégias que foram específicas para o aluno com TEA e cinco foram usuais para todos os alunos.

As finalidades das estratégias, descritas na Tabela 2, são importantes para que outros PEF possam fazer uso desse conhecimento que foi sistematizado.

Os dados também permitem concluir que as estratégias identificadas e descritas, utilizadas pelo PEF, não são usadas linearmente, mas são originárias das interações que acontecem no momento do ensino, sendo necessário a flexibilidade e intuição do professor para escolher novas estratégias quando percebe que as que usa não funcionam naquela situação. Entra em cena a intenção do professor, que, teoricamente, é uma das partes da definição adotada de estratégia de ensino.

O uso de estratégias de ensino nas aulas de Educação Física, apresentadas pela publicações nacionais e internacionais, puderam ser corroborados, porém, o estudo traz um avanço nesse tema: não só identifica a estratégia, mas a descreve contextualmente, indicando suas finalidades e seus mecanismos de ação.

Por fim, o estudo permite afirmar que, numa situação de ensino, muitas estratégias podem estar presentes em um único episódio interativo, elas podem ser combinadas entre si para alcançar sua funcionalidade naquele contexto de ensino.

\section{REFERÊNCIAS}

AMERICAN PSYCHIATRIC ASSOCIATION (APA). Manual Diagnóstico e Estatístico de Transtornos Mentais. DSM-5. Porto Alegre: Artmed, 2014.

AUXTER, David et al. Principles and methods of adapted physical education and recreation. 11th ed. New York: McGraw-Hill, 2010. p. 517-547.

BEZERRA, Alex Fabiano Santos. Estratégias para o ensino inclusivo de alunos com deficiência nas aulas de Educação Física. 2010. 108f. Tese (Doutorado em Educação) - Faculdade de Filosofia e Ciências, Universidade Estadual Paulista, Marília, 2010.

BRASIL. Casa Civil. Lei n. 12.764, de 27 de dežembro de 2012. Institui a Política nacional de proteção dos direitos da pessoa com transtorno do espectro autista; e altera o $\$ 3^{\circ}$ do art. 98 da Lei n. 8.112, de 11 de dezembro de 1990. Brasília, DF, 2012.

BRASIL. Politica nacional de educação especial na perspectiva da educação inclusiva. Secretaria de Educação Especial/MEC. Brasília, DF, 2008.

CRAFT, Diane H. A focus on inclusion in physical education. In: HENESSY, Betty (ed.). Physical education source-book. Champaign: Human Kinetics, 1996.

FARINHA, Ana Paula Vidotto. Inclusão de autistas nas aulas de educação física: possibilidades pedagógicas que podem auxiliar em suas potencialidades. 2012. 40f. Trabalho de Conclusão de Curso (Especialização) - Universidade Tecnológica Federal do Paraná, Medianeira, 2012.

FIORINI, Maria Luiza Salzani; MANZINI, Eduardo José. Dificuldades e sucessos de professores de educação física em relação à inclusão escolar. Revista Brasileira de Educação Especial, Marília, v. 22, n. 1, p. 49-64, 2016.

FIORINI, Maria Luiza Salzani; MANZINI, Eduardo José. Formação do professor educação física para inclusão de alunos com deficiência. Poiésis Pedagógica, Catalão, v. 12, n. 1, p. 94-109, 2014. 
FIORINI, Maria Luiza Salzani; MANZINI, Eduardo José. Estratégias de professores de educação física para promover a participação de alunos com deficiência auditiva nas aulas. Revista Brasileira de Educação Especial, Bauru, v. 18, p. 183-198, 2018.

FITTIPALDI-WERT, Jeanine; MOWLING, Claire. Using visual supports for students with autism in physical education. Journal of Physical Education, Recreation \& Dance, Reston, v. 80, n. 2, p. 39-43, 2009.

FOLSOM-MEEK, Sherry L.; AIELLO, Rocco A. Instruction strategies. In: LIEBERMAN, Lauren J. (org.). Paraeducators in physical education: a training guide to roles and responsibilities. New York: Human Kinetics, 2007. p. 47-60.

GRENIER, Michelle; YEATON, Pat. Previewing: a successful strategy for students with autism. Journal of Physical Education, Recreation \& Dance, Reston, v. 82, n. 1, p. 28-44, 2011.

HOUSTON-WILSON, Cathy; LIEBERMAN, Lauren J. Strategies for teaching students with autism in physical education. Journal of Physical Education, Recreation \& Dance, Reston, v. 74, n. 6; p. 40-44, 2003.

IÑESTA, Emilio Ribes. Técnicas de modificação do comportamento: aplicação ao atraso de desenvolvimento. Goiânia: E.P.U., 1974.

LIEBERMAN, Lauren J.; HOUSTON-WILSON, Cathy. Strategies for inclusion: a handbook for physical educators. 2. ed. Champaign: Human Kinetics, 2009.

LINDSAY, Sally et al. Exploring teachers' strategies for including children with autism spectrum disorder in mainstream classrooms. International Journal of Inclusive Education, v. 18, n. 2, p. 101-122, 2014.

MANZINI, Eduardo José. Recurso pedagógico adaptado e estratégias para o ensino de alunos com deficiência física. In: MANZINI, Eduardo José; FUJISAWA, Dirce Shizuko (org.). Jogos e recursos para comunicação e ensino na educação especial. Marília: ABPEE, 2010. p. 117-138.

MEIRA, Luciano. Análise microgenética e videografia: ferramentas de pesquisa em psicologia cognitiva. Temas em Psicologia, Ribeirão Preto, v. 2, n. 3, p. 1-8, 1994.

MENEAR, Kristi Sayers; SMITH, Shannon C. Teaching physical education to students with autism spectrum disorders. Strategies, v. 24, n. 3, p. 21-24, 2011.

MENEAR, Kristi Sayers; NEUMEIER, William H. Promoting physical activity for students with autism spectrum disorder: barriers, benefits, and strategies for success. Journal of Physical Education, Recreation \& Dance, Reston, v. 86, n. 3, p. 43-48, 2015.

ODOM, Samuel L. Preschool inclusion: What we know and where we go from here. Topics in Early Childhood Special Education, v. 20, n. 1, p. 20-27, 2000.

PETERS, Leira Lira; ZANELLA, Andrea Vieira. Videografia e análise microgenética como ferramentas para a pesquisa em Educação Física escolar. In: VAZ, Alexandre Fernandez; SAYÃO, Débora Tomé; PINTO, Fábio Machado (org.). Educação do corpo e formação de professores: reflexões sobre a prática de ensino de educação física. Florianópolis: Ed. UFSC, 2002. p. 65-84.

SCHOPLER, Eric et al. Perfil Psicoeducacional Revisado (PEP-R). Avaliação e tratamento individualizado para crianças autistas e com transtornos do desenvolvimento. 1990.

SOUZA, Jéssica Rezende; ASSIS, Renata Machado. Alunos autistas nas aulas de educação física: limites e possibilidades do trabalho cotidiano. In: ENDIPE - Encontro Estadual de Didática e Práticas de Ensino, 6., 2015, Anápolis. Anais eletrônicos [...] Anápolis: PUC-Goiás, 2015. p. 1-12. 
TOMÉ, Maycon Cleber. Educação física como auxiliar no desenvolvimento cognitivo e corporal de autistas. Movimento \& Percep̧ãa, Espírito Santo do Pinhal, v. 8, n. 11, p. 231-248, 2007.

VAZ, Renata Cristine Santos; SANTOS, Cristiane Silva. Inclusão e educação física escolar: realidade e possibilidades para o aluno com autismo na escola comum. Olhares \& Trilhas, Uberlândia, v. 10, n. 10, p. 49-63, 2009.

ZHANG, Jiabei; GRIFFIN, Ann J. Including children with autism in general physical education: eight possible solutions. Journal of Physical Education, Recreation \& Dance, Reston, v. 78, n. 3, p. 3350, 2007.

\section{Informações do(a)(s) autor(a)(es)}

Maria Luiza Salzani Fiorini

Faculdade de Ensino Superior do Interior Paulista (FAIP)

E-mail: salzanifiorini@yahoo.com.br

ORCID: https://orcid.org/0000-0002-9336-2136

Link Lattes: http://lattes.cnpq.br/6147381720599787

Eduardo José Manzini

Universidade Estadual Paulista (Unesp) - Marília

E-mail: eimanzini@uol.com.br

ORCID: https://orcid.org/0000-0002-7157-8227

Link Lattes: http://lattes.cnpq.br/9155295594995876 